\title{
Depósitos corneales producidos probablemente por ciprofloxacino tópico luego de entrecruzamiento o Cross-Linking corneal
}

\author{
Corneal deposits likely caused by topical ciprofloxacin after corneal cross-linking
}

Manuel Pérez-Martinot 1,a,b

\section{RESUMEN}

Hay medicamentos de uso tópico ocular como las fluoroquinolonas, que cuando son utilizadas en forma aislada o asociadas a otros fármacos pueden producir depósitos corneales en pacientes posoperados durante el período de desepitelización corneal. Presentamos el primer caso nacional reportado de una paciente con queratocono que presentó depósitos corneales luego de realizarse entrecruzamiento del colágeno corneal (CXL) probablemente debido al uso de ciprofloxacino y su evolución.

PALABRAS CLAVE: Oftalmología, cirugía, preparaciones farmacéuticas, opacidad de la córnea, complicaciones, efectos adversos. (Fuente: DeCS BIREME).

\section{SUMMARY}

There are ocular topical medicines like ciprofloxacin that when used alone or in combination can deposit on the cornea after surgical procedures during the period of cornel de-epithelization. We present here the first case reported in the country of a patient with keratoconus who presented corneal deposits after undergoing corneal cross-linking likely due to the use of topical ciprofloxacin.

KEYWORDS: Ophthalmology, corneal surgery, pharmaceutical preparations, corneal opacity, Drug-Related Side Effects and Adverse Reactions. (Source: MeSH NLM).

\section{INTRODUCCIÓN}

Diversos medicamentos de uso tópico, entre ellas las fluoroquinolonas, pueden producir depósitos corneales (1-5). Estos antibióticos bactericidas, se utilizan en oftalmología como profiláctico en el pre y postoperatorio, así como en el tratamiento de infecciones oculares.

El Cross-Linking (CXL) o entrecruzamiento de colágeno corneal es un tratamiento quirúrgico para la ectasia corneal como el queratocono y la ectasia postLASIK (queratomileusis in situ mediada por láser) con la finalidad de endurecer la capa de colágeno de la córnea (6).

En la literatura, no hay reportes de depósitos corneales asociados al uso de ciprofloxacino en el postoperatorio del cross-linking corneal por lo que se trataría del primer caso nacional reportado. El propósito de este reporte fue describir el caso de una paciente con queratocono que presentó depósitos

\footnotetext{
Facultad de Medicina, Universidad Peruana Cayetano Heredia. Lima, Perú.

Profesor Asociado.

Médico Oftalmólogo.
} 
corneales luego de realizarse entrecruzamiento del colágeno corneal (CXL), probablemente debido al uso de ciprofloxacino.

\section{PRESENTACIÓN DEL CASO}

Mujer de 26 años de edad, portadora de queratocono bilateral diagnosticado hace aproximadamente 10 años. Se realizó CXL en ambos ojos; el ojo izquierdo hace 4 años y en el derecho hace 10 meses. Ambos procedimientos fueron realizados por el mismo cirujano y con el mismo esquema terapéutico. Al mes del segundo procedimiento, presentó opacidad corneal en el ojo derecho. No refería molestias. El tratamiento tópico postoperatorio fue ciprofloxacino $3 \mathrm{mg} / \mathrm{ml} \mathrm{y}$ dexametasona $1 \mathrm{mg} / \mathrm{ml}$ gotas oftálmicas cuatro veces al día por 10 días. Luego que epitelizó la córnea, se retiró el lente de contacto terapéutico y se indicó fluorometalona acetato $1 \%$ en gotas oftálmicas qid por quince días y luego tid por quince días más. Además, se aplicó en forma simultánea desde el postoperatorio inmediato, metilcelulosa $1 \%$ en gotas oftálmicas cada 3 horas.

La agudeza visual preoperatoria corregida del ojo derecho fue de 0,5 y de 0,8 en el ojo izquierdo. Al mes, la agudeza visual corregida se mantuvo igual. A la biomicroscopia del ojo derecho, se observó depósito blanquecino en el área subepitelial corneal y del estroma anterior central con presencia de espacios no comprometidos. No había inyección conjuntival y la cámara anterior no presentaba alteraciones ni signos de infección o inflamación (figura 1). El examen de tomografía de coherencia óptica anterior comprobó la localización en el estroma anterior y subepitelial corneal de los depósitos (figura 2).

Se disminuyó la dosis de fluorometalona a dos veces al día por quince días asociada a metilcelulosa $1 \%$ tres veces al día. Durante los siguientes seis meses

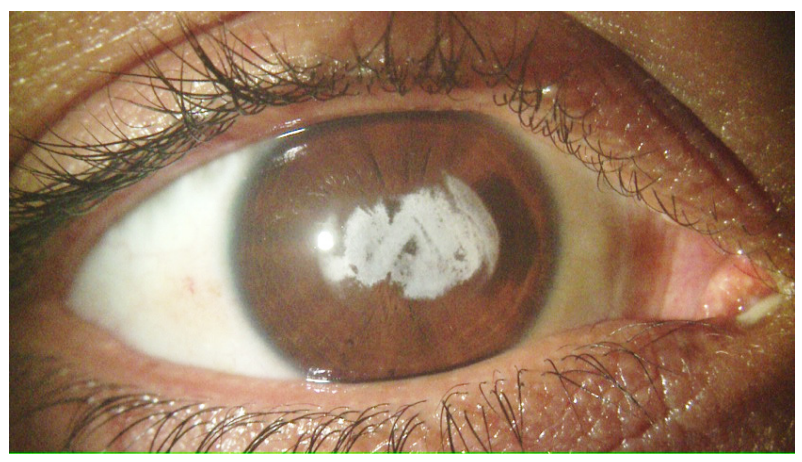

Figura 1 . Depósito corneal central inducido por ciprofloxacino.

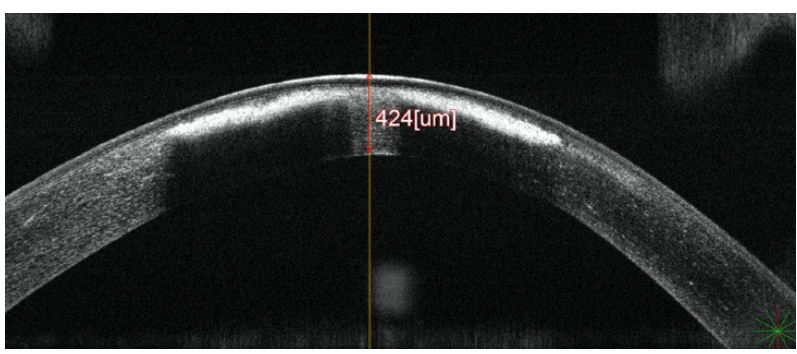

Figura 2. Tomografía de coherencia óptica anterior que muestra los depósitos a nivel subepitelial y en estoma anterior.

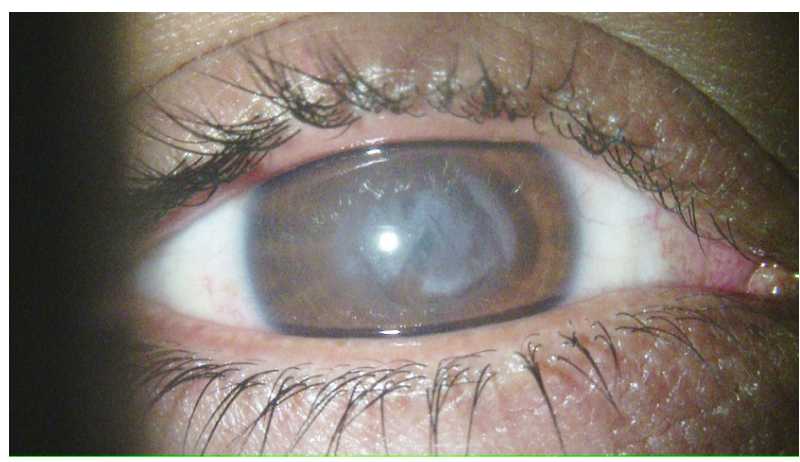

Figura 3. Control a los 6 meses, se observa resolución casi total de los depósitos, con cicatriz post CXL.

los depósitos corneales se fueron reabsorbiendo gradualmente, persistiendo aún la cicatriz producida por el CXL (figura 3).

\section{DISCUSIÓN}

Se han reportado depósitos corneales producidos por quinolonas de uso tópico como ciprofloxacino, ofloxacino, norfloxacino, gatifloxacino y tosufloxacino en la literatura extranjera (1-5). En un reporte se describe el caso de polifarmacia en una paciente adulta mayor luego de cirugía de catarata, en el que uno de los fármacos utilizados fue moxifloxacino tópico (5). Este sería el primer caso reportado a nivel nacional en el cual ocurren depósitos corneales debido a polifarmacia tópica (ciprofloxacino, dexametasona, fluorometalona y metilcelulosa) luego de cirugía corneal.

Se desconocen los factores predisponentes al depósito corneal debido a medicamentos tópicos, sin embargo, se mencionan algunos como el nivel del $\mathrm{pH}$, el edema corneal, el defecto epitelial corneal y polifarmacia en pacientes con compromiso de la epitelización corneal $(1,4,5)$.

En este caso, la paciente además de los depósitos corneales, presentó una cicatriz central con 
aplanamiento corneal como resultado del CXL. Al examen con lámpara de hendidura, se apreciaron los depósitos corneales por encima de esta cicatriz. La causa de los depósitos en esta paciente podría deberse al uso de ciprofloxacino y la polifarmacia utilizada durante el período de desepitelización corneal.

El diagnóstico es usualmente clínico, sin embargo, los depósitos corneales debido a fluoroquinolonas pueden ser confirmados en el laboratorio por análisis bioquímicos de biopsias corneales (5).

Los depósitos corneales suelen ocurrir a nivel del epitelio corneal, pero pueden ser también subepiteliales y en el estroma anterior $(1,2)$. En nuestra paciente, los depósitos fueron subepiteliales y en estroma anterior.

Los depósitos corneales debidos a gatifloxacino se resuelven luego de un mes de suspender la droga, mientras que en el caso de ciprofloxacino, esto suele ocurrir luego de más de 2 meses (1). En una serie de seis casos de depósitos por ofloxacino, sólo uno quedó con depósitos residuales luego de suspender la medicación (2). En nuestro caso con ciprofloxacino tópico, luego de seis meses de evolución, se evidenció una resolución casi completa de los depósitos corneales (figura 3), estando el paciente aún en observación.

En conclusión, el tratamiento tópico con ciprofloxacino asociado a polifarmacia en el postoperatorio de CXL puede producir depósitos corneales. La reabsorción de los mismos ocurre luego de suspender la medicación al cabo de varios meses sin mayores secuelas.

\section{Correspondencia:}

Dr. Manuel Pérez-Martinot

Correo electrónico: manuel.perez.m@upch.pe

\section{REFERENCIAS BIBLIOGRÁFICAS}

1. Vijay-Zawar S, Mahadik S. Corneal deposit after topical ciprofloxacin as postoperative medication after cataract surgery. Can J Ophthalmol. 2014; 49(4):392-394. DOI: 10.1016/j.jcjo.2014.04.013

2. Mitra A, Tsesmetzoglou E, McElvanney A. Corneal deposits and topical ofloxacin-the effect of polypharmacy in the management of microbial keratitis. Eye. 2007; 21(3):410-412. DOI: 10.1038/ sj.eye. 6702303

3. Elia M, Khodadadeh S, Chow J. Corneal crystalline deposits associated with topically applied gatifloxacin. Cornea. 2014; 33(6):638-639. DOI: 10.1097/ICO.0000000000000101

4. Kamiya K, Kitahara M, Shimizu K. Corneal deposits after topical tosufloxacin in a patient with poor tear secretion. Cornea. 2009; 28(1):114-115. DOI: 10.1097/ICO.0b013e3181822667

5. Babitha V, Prasannakumary C, Fathima Z, Raju KV. Postoperative corneal deposits the following polypharmacy. J Clin Ophthalmol Res. 2016; 4:155157. DOI: 10.4103/2320-3897.190789

6. Balparda K, Maldonado M. Corneal collagen crosslinking. A review of its clinical applications. Arch Soc Esp Oftalmol. 2017; 92(4):166-174. doi: 10.1016/j.oftal.2016.10.004

Recibido: 16/02/2020

Aceptado: 25/06/2020 